\title{
Prevalence of Burnout Syndrome and associated factors in medical students under different educational models
}

\author{
Thiago Santos Corrêa Prata1 $\oplus^{3}$, Dâmaris Alejandra Paula Calcides² $\oplus^{\circ}$,

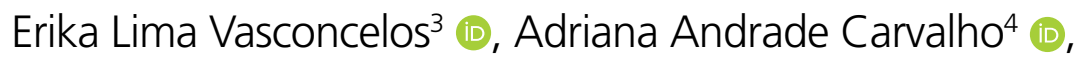 \\ Enaldo Vieira de Melo $^{5}\left(0\right.$, Edméa Fontes de Oliva-Costa ${ }^{5 *}$
}

\begin{abstract}
SUMMARY
OBJECTIVE: The objective of this study was to estimate the current prevalence of burnout syndrome among medical students at the Federal University of Sergipe and identify its associated factors.

METHODS: This cross-sectional study was conducted with medical students randomly selected between April and June 2019. This study compared two medical schools from the same university with different teaching models: the Federal University of Sergipe, Aracaju campus, with a traditional teaching model, and the Federal University of Sergipe Lagarto campus, with a problem-based learning teaching model. An online questionnaire on the sociodemographic characteristics, personal aspects, and educational process of the participants, in addition to the Malash Burnout Inventory-Student Survey questionnaire for screening burnout syndrome, was distributed to the participants. The descriptive analysis of the data, calculation of the prevalence ratios, and multivariate analysis by logistic regression were performed. RESULTS: This study included 213 students with an average age of $23 \pm 3.77$, and $50.2 \%$ of the students were male. Among the sample, $21.6 \%$ of the students met the three-dimensional criterion for burnout syndrome and $51.6 \%$ met the two-dimensional criterion. Burnout levels were higher in the students who rarely received the emotional support they needed in the program (OR 3.98), those who thought about dropping out of the undergraduate (OR 2.88), and those who considered their academic performance to be regular or weak (OR 12.1). The traditional teaching model was not a factor associated with burnout syndrome.

CONCLUSIONS: The results suggest that a high prevalence of burnout syndrome is associated with psychosocial factors and the educational processes of medical students.

KEYWORDS: Burnout, psychological. Students, medical. Mental health. Education, medical.
\end{abstract}

\footnotetext{
'Universidade Federal de Sergipe, Grupo de Estudos e Pesquisas em Psiquiatria, Saúde Mental e Educação para as Profissões da Saúde, Departamento de Medicina - Aracaju (SE), Brazil.

Universidade Federal de Sergipe, Grupo de Estudos e Pesquisas em Psiquiatria, Saúde Mental e Educação para as Profissões da Saúde, Hospital Universitário - Aracaju (SE), Brazil.

3Universidade Federal de Sergipe, Departamento de Medicina - Lagarto (SE), Brazil.

${ }^{4}$ Universidade Federal de Sergipe, Departamento de Farmácia - Lagarto (SE), Brazil.

${ }^{5}$ Universidade Federal de Sergipe, Departamento de Medicina - Aracaju (SE), Brazil.

*Corresponding author: edmeaolivacosta@gmail.com

Conflicts of interest: the authors declare there is no conflicts of interest. Funding: none.

Received on December 20, 2020. Accepted on March 14, 2021.
} 


\section{INTRODUCTION}

Burnout syndrome (BS) is defined as an inappropriate response to emotional stress and an excessive need to deal with chronic interpersonal stressors in the workplace ${ }^{1,2}$. Medical training is a significant source of stressors, such as the excessive course load, the large amount of program content, the requirement for excellent performance, and the need to deal with pain and death, which can contribute to mental health aggravations in medical students ${ }^{1,3,4}$.

Freudenberger ${ }^{5}$ scientifically reported on BS for the first time in 1974 . He characterized BS by observing that professionals who cared for other people developed exhaustion, isolation, and even secondary aggressiveness in response to their excessive use of energy, force, and resources and that members of the workforce could become inoperative 5 . Maslach organized BS into three dimensions, namely, emotional exhaustion, cynicism, and low professional efficacy, from a sociopsychological perspective in workers and students ${ }^{1,2}$.

The effects of inadequate prevention and delayed detection of BS can be observed at all stages of the medical career. An increase in suicidal ideation, substance abuse, and medical errors, in addition to a decrease in professionalism and the development of difficult relationships with patients are associated with $\mathrm{BS}^{6}$. Similarly, the consequences of BS during medical training can be recognized, such as a negative impact on academic life and general well-being; in addition, BS is an independent predictor of worse quality of life ${ }^{7}$.

Exposure to stressors during undergraduate school can affect the performance, mental health, and future professional life of students. Therefore, alternative methods need to be developed, which allow early detection and intervention of BS.

This study aims to estimate the current prevalence of BS in medical students and identify its associated factors at two medical schools from the same institution, the Federal University of Sergipe (UFS), employing different educational models to stimulate the planning of preventive measures.

\section{METHODS}

\section{Study site}

We conducted this study simultaneously in two medical schools of the same public university in the state of Sergipe, Brazil. The Federal University of Sergipe Aracaju campus (UFS-AJU) is 59 years old and is located in the state capital; it adopts a traditional model of teaching. It divides the curriculum into six years: the first two years focus on knowledge of basic biological sciences, the following two years are dedicated to understanding the medical sciences, and the mandatory medical internships are completed in the last two years.
The Federal University of Sergipe Lagarto campus (UFSLAG) is nine years old and is located in the interior of the state of Sergipe; it adopts an active teaching method, namely, problem-based learning (PBL). PBL is an interdisciplinary model that involves building knowledge based on real or simulated problems. Thus, students are active in the learning process.

\section{Study population}

Any students enrolled in medical school courses in either school were eligible to participate. This study sample was not randomized, and the medical students were selected consecutively to reduce sample bias.

We used G*Power software version 3.1.9.4 (2019) to estimate the sample size, using an alpha of 0.05 and a power of 0.8 , whereas the expected ratio of UFS-AJU to UFS-LAG students was assumed to be $2(0.25 / 0.125)$, and the expected sample size was 163 students from UFS-AJU and 81 students from UFS-LAG. However, 133 students at UFS-AJU and 80 at UFS-LAG volunteered to participate.

\section{Study design}

This was an analytical cross-sectional observational study, with data collected between April and June 2019.

\section{Data collection}

The data were collected using a form sent by email and social media from all students enrolled at both schools.

\section{Instruments}

Using an electronic form, we distributed two self-administered questionnaires. The first was a structured questionnaire with 28 precoded, close-ended questions about socioeconomic and demographic characteristics, personal aspects, and the educational process that were designed by the authors and that had been tested and improved in earlier studies ${ }^{1,4,8,9}$.

The second questionnaire was the Maslach Burnout Inventory Student Survey (MBI-SS), adapted and validated in English and Portuguese ${ }^{10,11}$. This questionnaire comprises 15 items on the three dimensions of BS: emotional exhaustion (five items), cynicism (four items), and professional efficacy (six items). The following Likert scale was used to measure the frequency of each item: 0 (never), 1 (once a year or less), 2 (once a month or less), 3 (sometimes a month), 4 (once a week), 5 (a few times a week), and 6 (every day).

Maroco and Tecedeiro established the following thresholds for each dimension in the Portuguese translation of the MBI-SS: emotional exhaustion (low $<10$, moderate 10-14, and high $>14$ ), cynicism (low $<2$, moderate $2-6$, and high $>6$ ), and professional efficacy (low $<23$, moderate $23-27$, and 
high >27). High emotional exhaustion and cynicism scores, in addition to low levels of professional efficacy, were used as the three-dimensional criterion to determine BS. The two-dimensional criterion was defined by high exhaustion and cynicism ${ }^{12}$.

\section{Data analysis}

We created a database of the questionnaire records using the trial version of IBM SPSS. The statistical analysis comprised of three stages as follows:

1. The calculation of descriptive statistics to characterize the population profile.

2. Simple analysis, elaboration of tables, calculation of the prevalence ratios and their confidence intervals (95\%), stratified analysis, and calculation of the adjusted prevalence ratios.

3. The analysis of multiple variables by logistic regression. We included variables that showed an association with the outcome in the model $(\mathrm{p} \leq 0.25)$. The final model contained only the independent variables that maintained an association with the outcome after adjustment $(\mathrm{p} \leq 0.05)$ based on the likelihood ratio test.

\section{ETHICAL CONSIDERATIONS}

The Human Research Ethics Committee of UFS approved the study under CAAE 92970618.3.0000.5546. Each participant had the right to refuse to participate in this study or withdraw their authorization, and the participants were guaranteed the confidentiality of the data provided.

\section{RESULTS}

A total of 213 students participated in this study, 133 of whom were from UFS-AJU (62.4\%) and 80 of whom were from UFSLAG (37.6\%); the students had an average age of $23 \pm 3.77$, with a minimum age of 17 years and a maximum age of 37 years. A total of $50.2 \%$ of the students were male and $93.4 \%$ were single. Table 1 summarizes the main variables based on the descriptive analysis of our sample by school of origin.

Most students (60.6\%) were from outside the city where their schools were located, with $35.7 \%$ from other states and $24.9 \%$ from inland cities (excluding the capital), while $39.4 \%$ were from the capital. Furthermore, $84 \%$ of the students had only studied and had not worked, $56.3 \%$ lived with family members, $74.6 \%$ did not receive academic assistance, $51.2 \%$ practiced a certain religion, and $74.2 \%$ had no medical relatives.

Virtually, all students (96.2\%) were satisfied with their careers in medicine. However, $51.2 \%$ of the students considered themselves to have regular or weak academic performance and only $45.5 \%$ considered the medical degree to be consistent with expectations. Concerning the educational process, $38.0 \%$ of the students were satisfied with the teaching and learning strategies of the program, while $41.8 \%$ had considered dropping out of the undergraduate.

In terms of emotional support provided during the program, $46.9 \%$ of the students indicated that they received support occasionally or rarely. Most of the students slept $<8 \mathrm{~h} /$ day (97.6\%). Previously diagnosed mental health conditions were reported by $21.6 \%$ of the students, and the use of psychiatric medicines prescribed by a doctor was reported by $27.2 \%$ of the students. Most students indicated that they had not consumed legal (55.4\%) or illegal (69.0\%) psychoactive substances.

In terms of experiences of serious illness within the family, $59.6 \%$ of the students reported such experiences. In conflict situations, $46.5 \%$ indicated that they engaged in dialogue. A little over half (55.4\%) were physically active. Regarding the use of mobile phones and social networks, $51.2 \%$ felt uncomfortable when they did not use them for a while. A maximum duration of social media usage of $3 \mathrm{~h}$ /day was reported by $60.1 \%$ of the students.

The overall prevalence of BS was $21.6 \%$, based on the three-dimensional criterion, with prevalences of $25.6 \%$ at UFS-AJU and $15 \%$ at UFS-LAG. Based on the two-dimensional criterion, the prevalence was $51.6 \%$. Table 2 characterizes the sample studied according to the presence or absence of BS. After assessing each dimension, we found a high level of emotional exhaustion, with a prevalence of $71.4 \%$; a high level of cynicism, with a prevalence of $57.3 \%$; and low professional effectiveness, with a prevalence of $25.8 \%$ (Table 3).

In the last stage of the data analysis with logistic regression, the factors most strongly associated with $\mathrm{BS}$ were rarely receiving the emotional support needed during the program (OR 3.98; $\mathrm{p}=0.001$ ), thinking about dropping out of the undergraduate (OR 2.88; $\mathrm{p}=0.01$ ) and considering one's academic performance to be regular or weak (OR 12.1; $<<0.0001)$. The different teaching models (i.e., traditional and $\mathrm{PBL}$ ) in each school did not prove to be an associated factor with BS.

\section{DISCUSSION}

The prevalence of $\mathrm{BS}$ was $21.6 \%$ based on the three-dimensional criterion. At the UFS-AJU, the frequency has increased over the past few years. Previous studies in 2018 with interns and in 2009 with students of all levels showed that the prevalence of BS was $10.3 \%^{1,4}$. In our study, BS was present in $25.6 \%$ of the students. This incidence is higher than the national average $(13.1 \%)$ but lower than the overall estimate $(44.2 \%)^{13,14}$. 
Table 1. Descriptive analysis of socioeconomic, psychosocial, and educational variables among medical students attending medical schools with different educational models at a public university, Aracaju, Brazil, 2019.

\begin{tabular}{|c|c|c|}
\hline & $\begin{array}{l}\text { UFS-AJU } \\
(n=133)\end{array}$ & $\begin{array}{c}\text { UFS-LAG } \\
(n=80)\end{array}$ \\
\hline Prevalence of Burnout Syndrome (\%) & $34(25.6)$ & $12(15)$ \\
\hline Mean age (years) & $22.9 \pm 3.5$ & $23.2 \pm 4.2$ \\
\hline \multicolumn{3}{|l|}{ Gender } \\
\hline Male & 69 & 38 \\
\hline \multicolumn{3}{|l|}{ Civil status } \\
\hline Single & 126 & 73 \\
\hline Married & 7 & 6 \\
\hline Separated/divorced & 0 & 1 \\
\hline \multicolumn{3}{|l|}{ Program stage } \\
\hline Basic cycle (1st and 2 nd year) & 28 & 28 \\
\hline Clinical cycle (3rd and 4th year) & 74 & 28 \\
\hline Internship (5th and 6th year) & 31 & 24 \\
\hline \multicolumn{3}{|c|}{ Family income (in number of minimum wages) } \\
\hline $1-10$ & 87 & 65 \\
\hline$>10-20$ & 34 & 10 \\
\hline$>20$ & 12 & 5 \\
\hline \multicolumn{3}{|l|}{ Satisfaction with medical school } \\
\hline Satisfied & 66 & 39 \\
\hline Partially satisfied & 57 & 37 \\
\hline Dissatisfied & 10 & 4 \\
\hline \multicolumn{3}{|l|}{ Perception of academic performance } \\
\hline Regular or weak & 73 & 36 \\
\hline \multicolumn{3}{|c|}{ Level of agreement that the teaching and learning strategies of the program are satisfactory } \\
\hline Agree & 37 & 44 \\
\hline Undecided & 56 & 28 \\
\hline Disagree & 40 & 8 \\
\hline \multicolumn{3}{|l|}{ Failed a course subject } \\
\hline No & 118 & 73 \\
\hline \multicolumn{3}{|c|}{ Has considered dropping out of the undergraduate } \\
\hline Yes & 53 & 36 \\
\hline \multicolumn{3}{|l|}{ Emotional support during the program } \\
\hline Always or occasionally & 62 & 51 \\
\hline Rarely & 71 & 29 \\
\hline \multicolumn{3}{|l|}{ Diagnosis with mental health problems } \\
\hline Yes & 33 & 13 \\
\hline
\end{tabular}

UFS-AJU: Universidade Federal de Sergipe - Aracaju; UFS-LAG: Universidade Federal de Sergipe - Lagarto. 
An analysis of foreign studies observed a prevalence of BS of $38.2 \%$ among the undergraduates from Saudi Arabia ${ }^{15}$, $26.7 \%$ among students from the United Kingdom ${ }^{16}$, and $77 \%$ from New Zealanders ${ }^{17}$. In the United States, a study using the two-dimensional criterion found a prevalence of $35.2 \%$ among medical students at several universities across the country, which was lower than that found in this study $(51.6 \%)^{6}$. Geographic location may be implicated in the prevalence of BS, with Oceania and part of the Middle East having higher levels of burnout than Central and South America and Europe ${ }^{14}$.
Previous studies at the same institution indicated that medical students had a high level of mental illness. This population had high levels of depressive symptoms and common mental disorders, which were strongly associated with factors related to the teaching-learning sphere ${ }^{8,9}$.

The evaluations of each subscale indicated high rates of emotional exhaustion and cynicism but low rates of low professional efficacy (Table 3), consistent with the literature ${ }^{1,4,14}$. Some authors have hypothesized that high scores in a specific dimension can precipitate an imbalance among other

Table 2. Distribution of medical students from two medical schools at a public medical university $(\mathrm{n}=213)$ by socioeconomic, psychosocial, and educational characteristics and prevalence of burnout syndrome, Aracaju, Brazil, 2019.

\begin{tabular}{|c|c|c|c|}
\hline & $\begin{array}{l}\text { With BS } \\
(n=46)\end{array}$ & $\begin{array}{l}\text { Without BS } \\
\qquad(n=167)\end{array}$ & $p$ \\
\hline \multicolumn{4}{|l|}{ Gender } \\
\hline Female & 25 & 81 & \multirow{2}{*}{0.126} \\
\hline Male & 21 & 86 & \\
\hline \multicolumn{4}{|l|}{ Civil status } \\
\hline Single & 44 & 155 & \multirow{3}{*}{0.126} \\
\hline Married & 1 & 12 & \\
\hline Separated/divorced & 1 & 0 & \\
\hline \multicolumn{4}{|c|}{ Family income (in the number of minimum wages) } \\
\hline $1-10$ & 36 & 116 & \multirow{3}{*}{0.485} \\
\hline$>10-20$ & 8 & 36 & \\
\hline$>20$ & 2 & 15 & \\
\hline \multicolumn{4}{|l|}{ Program stage } \\
\hline Basic cycle (1st and 2nd year) & 3 & 53 & \multirow{3}{*}{0.001} \\
\hline Clinical cycle (3rd and 4th year) & 30 & 72 & \\
\hline Internship (5th and 6th year) & 13 & 42 & \\
\hline \multicolumn{4}{|l|}{ Educational institution } \\
\hline UFS-AJU & 34 & 99 & \multirow{2}{*}{0.048} \\
\hline UFS-LAG & 12 & 68 & \\
\hline \multicolumn{4}{|l|}{ Perception of academic performance } \\
\hline Good & 4 & 100 & \multirow{2}{*}{$<0.0001$} \\
\hline Regular or weak & 42 & 67 & \\
\hline \multicolumn{4}{|c|}{ Emotional support during the program } \\
\hline Always or occasionally & 11 & 102 & \multirow{2}{*}{$<0.0001$} \\
\hline Rarely & 35 & 65 & \\
\hline \multicolumn{4}{|c|}{ Has considered dropping out of the undergraduate } \\
\hline Yes & 33 & 56 & \multirow{2}{*}{$<0.0001$} \\
\hline No & 13 & 111 & \\
\hline
\end{tabular}

UFS-AJU: Universidade Federal de Sergipe - Aracaju; UFS-LAG: Universidade Federal de Sergipe - Lagarto; BS: Burnout Syndrome. 
Table 3. Prevalence of burnout syndrome and levels of each dimension* among medical students from two medical schools at a Brazilian public university, Aracaju, Brazil, 2019.

\begin{tabular}{|c|c|c|}
\hline & $n=213$ & $\%$ \\
\hline $\begin{array}{l}\text { Burnout syndrome, three- } \\
\text { dimensional }\end{array}$ & 46 & 21.6 \\
\hline $\begin{array}{l}\text { Burnout syndrome, two- } \\
\text { dimensional (emotional } \\
\text { exhaustion and cynicism) }\end{array}$ & 110 & 51.6 \\
\hline \multicolumn{3}{|l|}{ Emotional exhaustion } \\
\hline Low $(<10)$ & 24 & 11.3 \\
\hline Moderate (10-14) & 37 & 17.4 \\
\hline High (>14) & 152 & 71.4 \\
\hline \multicolumn{3}{|l|}{ Cynicism } \\
\hline Low $(<2)$ & 22 & 10.3 \\
\hline Moderate (2-6) & 69 & 32.4 \\
\hline $\operatorname{High}(>6)$ & 122 & 57.3 \\
\hline \multicolumn{3}{|l|}{ Professional efficacy } \\
\hline High (>27) & 119 & 55.9 \\
\hline Moderate (23-27) & 39 & 18.3 \\
\hline Low $(<23)$ & 55 & 25.8 \\
\hline
\end{tabular}

*The scores of the levels of each dimension are based on Maroco and Tecedeiro ${ }^{12}$.

dimensional scores ${ }^{1}$. Imbalance in a single dimension can cause disadvantages to medical training. For example, high cynicism during a medical program can lead to serious problems in the doctor-patient relationship, such as difficulty in communicating bad news ${ }^{18}$.

The main point of comparison in this study was between two medical schools from the same Brazilian public university with different methodologies. PBL, a method that encourages active knowledge seeking, has been identified as a potential protective factor against BS development, especially in schools with good planning and good curriculum management $^{3,19}$. However, the use of either the traditional teaching method (practiced at UFS-AJU) or the PBL method (practiced at UFS-LAG) did not appear to be a factor associated with BS in this study.

The presence of BS was statistically associated with rarely receiving emotional support in this study. There are several important conditions that promote coping with stressors during undergraduate school, such as the existence of a supportive culture in educational institutions through the encouragement of support among colleagues, family networks, extracurricular activities, and counseling ${ }^{20}$. However, even when such support is available, students avoid seeking professional help to mediate emotional or mental health problems because of the personal or cultural stigma perceived by the student and negative personal experiences $^{21}$. Frajerman ${ }^{22}$ suggested that mental health care for medical students must be comprehensive and that prevention must be carried out at the primary, secondary, and tertiary levels through institutional, group, and individual interventions ${ }^{22}$.

The UFS-LAG has a structured psychosocial support network with social workers and psychologists, as well as support, if necessary, from a psychiatrist and pedagogue, that is readily available to students. Workshops on integrative and complementary health practices are also available to the entire academic community. These measures may be related to the lower levels of BS present in this population.

Interns at UFS-AJU had access to a Balint group (BG) for approximately 10 weeks during the mental health internship until its suspension in May 2019 by management; participation in the BG was associated with a reduction in the prevalence of $\mathrm{BS}$ and the mitigation of vulnerability factors among medical interns at this school ${ }^{4}$. Students at UFS-AJU only had access to the psychologist through the General Student Assistance Service of the University on another campus. When they needed psychiatric care, the student had to compete for openings in the general psychiatry outpatient clinic of the University Hospital of UFS or look for services outside the university since there is no exclusive psycho-pedagogical, psychological, and psychiatric support service for students on this campus.

A reliance on tests to assess students' performance, as at UFS-AJU, may be related to a greater chance of the development of BS among students who consider their academic performance to be regular or weak. These students may see their poor performance on tests as poor progress in the program, which can generate the desire to leave the undergraduate. As demonstrated in previous studies, the use of tests for performance evaluation is an important source of stress among medical students ${ }^{23,24}$.

The percentage of students reporting a previously diagnosed mental disorder was the same as the percentage of student reporting BS (21.6\%). This may be an overlap of diagnoses and may constitute a limitation of the study. Some mental disorders, such as depressive disorder or anxiety disorder, exhibit symptoms that fall within the first dimension of the BS scale (exhaustion). The difference is that psychological distress in SB is directly related to the professional environment.

However, we believe that we have fulfilled our aim in this cross-sectional study. In this type of study, we cannot test causality because exposure and effect occur simultaneously. Nonetheless, we highlight the importance of planning preventative measures. 


\section{CONCLUSIONS}

The prevalence of BS was high in this study. Factors related to the psychosocial and educational spheres of medical students are associated with BS, but the teaching model adopted is not.

The medical schools surveyed and others with similar profiles should reflect on the role they play in the promotion and prevention of psychological distress. Further longitudinal studies could strengthen our findings.

\section{AUTHORS' CONTRIBUTIONS}

TP: Data curation, Formal Analysis, Writing - original draft, Writing - review \& editing. EM: Conceptualization, Data curation, Formal Analysis, Writing - original draft, Writing - review \& editing. EOC: Conceptualization, Data curation, Formal Analysis, Writing - review \& editing. AC: Conceptualization, Data curation, Formal Analysis, Writing - review \& editing. DC: Data curation, Formal Analysis, Writing - review \& editing. EV: Data curation, Formal Analysis, Writing - review \& editing.

\section{REFERENCES}

1. Costa EF, Santos SA, Santos AT, Melo EV, Andrade TM. Burnout Syndrome and associated factors among medical students: a cross-sectional study. Clinics (Sao Paulo). 2012;67(6):573-80. https://doi.org/10.6061/clinics/2012(06)05

2. Maslach C, Leiter MP. Understanding the burnout experience: recent research and its implications for psychiatry. World Psychiatry. 2016;15(2):103-11. https://doi.org/10.1002/ wps.20311

3. Barbosa ML, Ferreira BLR, Vargas TN, Ney da Silva GM, Nardi $A E$, Machado $S$, et al. Burnout prevalence and associated factors among Brazilian medical students. Clin Pract Epidemiol Ment Health. 2018;14:188-95. https://doi. org/10.2174/1745017901814010188

4. Calcides DAP, Didou RDN, Melo EV, Oliva-Costa EF. Burnout Syndrome in medical internship students and its prevention with Balint Group. Rev Assoc Med Bras (1992). 2019;65(11):1362-7. https://doi.org/10.1590/1806-9282.65.11.1362

5. Freudenberger HJ. Staff Burn-Out. J Soc Issues. 1974;30(1):15965. https://doi.org/10.1111/j.1540-4560.1974.tb00706.x

6. Dyrbye LN, West CP, Satele D, Boone S, Tan L, Sloan J, et al. Burnout among U.S. medical students, residents, and early career physicians relative to the general U.S. population. Acad Med. 2014;89(3):443-51. https://doi.org/10.1097/ ACM.0000000000000134

7. Solis AC, Lotufo-Neto F. Predictors of quality of life in Brazilian medical students: a systematic review and meta-analysis. Braz J Psychiatry. 2019;41(6):556-67. https://doi.org/10.1590/15164446-2018-0116

8. Costa EFO, Mendes CMC, Andrade TM. Common mental disorders in medical students: A repeated cross-sectional study over six years. Rev Assoc Med Bras. 2017;63(9):771-8. https://doi.org/10.1590/1806-9282.63.09.771

9. Costa EF, Santana YS, Santos AT, Martins LA, Melo EV, Andrade TM. Sintomas depressivos entre internos de medicina em uma universidade pública brasileira. Rev Assoc Med Bras. 2012;58(1):53-9. https://doi.org/10.1590/S010442302012000100015

10. Campos JADB, Maroco J. Adaptação transcultural PortugalBrasil do Inventário de Burnout de Maslach para estudantes. Rev Saude Publica. 2012;46(5):816-24. Portuguese. https:// doi.org/10.1590/s0034-89102012000500008

11. Maslach C, Jackson SE, Leiter MP. The Maslach burnout inventory manual. In: Zalaquett CP, Wood RJ. Evaluating stress: a book of resources. 3rd ed. Lanham: The Scarecrow Press; 1997. p.191-218.
12. Maroco J, Tecedeiro M. Inventário de Burnout de Maslach para estudantes portugueses. Psic, Saúde \& Doenças. 2009 [cited on Nov. 20, 2020];10(2):227-35. Available from: http:// www.scielo.pt/scielo.php?script=sci_arttext\&pid=S164500862009000200007\&lang=pt

13. Pacheco JP, Giacomin HT, Tam WW, Ribeiro TB, Arab C, Bezerra $I M$, et al. Mental health problems among medical students in Brazil: a systematic review and meta-analysis. Braz J Psychiatry. 2017;39(4):369-78. https://doi.org/10.1590/1516-4446-20172223

14. Frajerman A, Morvan Y, Krebs MO, Gorwood P, Chaumette B. Burnout in medical students before residency: a systematic review and meta-analysis. Eur Psychiatry. 2019;55:36-42. https://doi. org/10.1016/j.eurpsy.2018.08.006

15. Shadid A, Shadid AM, Shadid A, Almutairi FE, Almotairi KE, Aldarwish T, et al. Stress, Burnout, and associated risk factors in medical students. Cureus. 2020;12(1):e6633. https://doi. org/10.7759/cureus.6633

16. Cecil J, McHale C, Hart J, Laidlaw A. Behaviour and burnout in medical students. Med Educ Online. 2014;19:25209. https:// doi.org/10.3402/meo.v19.25209

17. Farrell SM, Moir F, Molodynski A, Bhugra D. Psychological wellbeing, burnout and substance use amongst medical students in New Zealand. Int Rev Psychiatry. 2019;31(7-8):630-6. https://doi.org/ 10.1080/09540261.2019.1681204

18. Brown R, Dunn S, Byrnes K, Morris R, Heinrich P, Shaw J. Doctors' stress responses and poor communication performance in simulated bad-news consultations. Acad Med. 2009;84(11):1595-602. https://doi.org/10.1097/ACM.0b013e3181baf537

19. Gomes R, Brino R de F, Aquilante AG, Avó LR da $S$ de. Aprendizagem baseada em problemas na formação médica e o currículo tradicional de medicina: uma revisão bibliográfica. Rev Bras Educ Med. 2009;33(3):433-40. https://doi.org/10.1590/ S0100-55022009000300014

20. Chang E, Eddins-Folensbee F, Coverdale J. Survey of the prevalence of burnout, stress, depression, and the use of supports by medical students at one school. Acad Psychiatry. 2012;36(3):177-82. https://doi.org/10.1176/ appi.ap. 11040079

21. Dyrbye LN, Eacker A, Durning SJ, Brazeau C, Moutier C, Massie FS, et al. The impact of stigma and personal experiences on the help-seeking behaviors of medical students with Burnout. Acad Med. 2015;90(7):961-9. https://doi.org/10.1097/ACM.0000000000000655 
22. Frajerman $\mathrm{A}$. Which interventions improve the well-being of medical students? A review of the literature. Encephale. 2020;46(1):55-64. French. https://doi.org/10.1016/j. encep.2019.09.004

23. Anuradha R, Dutta R, Raja JD, Sivaprakasam P, Patil AB. Stress and Stressors among Medical Undergraduate Students: A Cross-sectional Study in a Private Medical College in
Tamil Nadu. Indian J Community Med. 2017;42(4):222-5. https://doi.org/10.4103/ijcm.IJCM_287_16

24. Weber J, Skodda S, Muth T, Angerer P, Loerbroks A. Stressors and resources related to academic studies and improvements suggested by medical students: a qualitative study. BMC Med Educ. 2019;19(1):312. https://doi. org/10.1186/s12909-019-1747-z 